\title{
PENGGUNAAN METODE FUZZY DALAM PENILAIAN TINGKAT KEMAMPUAN NON-AKADEMIK MAHASISWA MELALUI SATUAN KREDIT KEGIATAN MAHASISWA
}

\author{
Ni Putu Linda Santiari ${ }^{1}$ \\ ${ }^{1}$ STMIK STIKOM Bali \\ Email: 1santiarilinda@yahoo.id
}

(Naskah masuk: 1 Oktober 2016, diterima untuk diterbitkan: 26 Desember 2016)

\begin{abstract}
Abstrak
Pemberian point kegiatan non-akademik di STIKOM Bali dilakukan dengan menggunakan point SKKM (Satuan Kredit Kegiatan Mahasiswa).Satuan Kredit Kegiatan Mahasiswa (SKKM) adalah suatu pengakuan dan penilaian terhadap kegiatan yang diikuti oleh mahasiswa STMIK STIKOM Bali dalam pengembangan kegiatan kemahasiswaan.Pengakuan dan penilaian kegiatan yang diikuti dinyatakan dalam bentuk Satuan Kredit Kegiatan Mahasiswa (SKKM). Besarnya pembobotan SKKM yang diberikan disesuaikan dengan jenis dan pelaksanaan kegiatan yang diikuti. Saat ini penghitungan point SKKM masih dilakukan manual dan belum bisa menilai tingkat kemampuan non akademik mahasiswa. Terkait belum adanya cara untuk menilai tingkat prestasi nonakademik mahasiswa sehingga bagian kemahasiswaan tidak dapat menentukan kebijakan apa yang harus diambil untuk mengukur tingkat prestasi non akademik mahasiswa. Berdasarkan informasi di atas, penulis mencoba untuk membuat dan merancang logika fuzzy untuk membantu bagian kemahasiswaan dalam mengevaluasi tingkat prestasi non akademik mahasiswa melalui Satuan Kredit Kegiatan Mahasiswa. Penulis berharap hasil dari evaluasi ini dapat membantu bagian kemahasiswaan dalam menilai tingkat prestasi non akademik mahasiswa melalui Satuan Kredit Kegiatan Mahasiswa dan mengambil langkah berikutnya dari penilaian tersebut. Data sample yang digunakan adalah 10 mahasiswa yang memiliki SKKM.
\end{abstract}

Kata kunci: Fuzzy, SKKM, Non-akademik

\begin{abstract}
Granting point non-academic activities in Bali STIKOM done using point SKKM (Satuan Kredit Kegiatan Mahasiswa). SKKM is a recognition and assessment of the activities pursued by students STMIK STIKOM Bali in the development and assessment activities of student affairs. Recognition of the activities pursued expressed in the form of SKKM. The amount of weighting SKKM is adjusted to the type and implementation of the activities pursued. Metering point SKKM still done manually and not able to assess the level of non-academic abilities of students. Related lack way to assess the non-academic achievements of the student so that the student can not determine what policy should be taken to measure the level of non-academic achievements of students. Based on the above information, the author tries to create and design a fuzzy logic to help the student section in evaluating the level of non-academic achievements of students through the SKKM. The authors hope the results of this evaluation can help the Student Council in assessing the level of non-academic achievements of students through the Student Activity Credit Unit and take the next step of the assessment. The data sample used was 10 students who have SKKM.
\end{abstract}

Keywords: Fuzzy, SKKM, Non-academic

\section{PENDAHULUAN}

Logika fuzzy merupakan salah satu komponen pembentuk soft computing. Logika fuzzy pertama kali diperkenalkan oleh Prof. Lotfi A. Zadeh pada tahun 1965. Dasar dari logika fuzzy adalah teori himpunan fuzzy. Pada teori himpunan fuzzy, peranan derajat keanggotaan sebagai penentu keberadaaan elemen dalam suatu himpunan sangatlah penting. Nilai keanggotaan atau derajat keanggotaan atau membership function menjadi ciri utama dari penalaran dengan logika fuzzy tersebut (Kusuma Dewi, 2010).

Satuan Kredit Kegiatan Mahasiswa (SKKM) adalah suatu pengakuan dan penilaian terhadap kegiatan yang diikuti oleh mahasiswa STMIK STIKOM Bali dalam pengembangan kegiatan kemahasiswaan. Pengakuan dan penilaian kegiatan yang diikuti dinyatakan dalam bentuk Satuan Kredit Kegiatan Mahasiswa (SKKM). Besarnya pembobotan SKKM yang diberikan disesuaikan 
dengan jenis dan pelaksanaan kegiatan yang diikuti (SKKM STIKOM Bali, 2015).

Penulis dalam hal ini menggunakan metode Fuzzy dibandingkan dengan metode metode yang lain karena ada beberapa kelebihan. metode fuzzy mamdani dan sesuai digunakan dalam penelitian untuk menilai tingkat kemampuan non-akademik mahasiswa melalui satuan kredit kegiatan mahasiswa diantaranya adalah pembentukan himpunan fuzzy yang sesuai dengan kebutuhan dalam penelitian, komposisi aturan aturan yang sesuai dan penegasan (defuzy) untuk mencari nilai yang bergerak secara halus sehingga perubahan dari suatu himpunan fuzzy juga akan berjalan secara halus dan lebih mudah dalam perhitungan. Penulis menggunakan metode fuzzy mamdani karena metode ini telah berhasil dipergunakan dalam penelitian Syaeful Anas Aklani tahun 2014 yang berjudul Metode Fuzzy Logic Untuk Evaluasi Kinerja Pelayanan Perawat (Studi Kasus: RSIA Siti Hawa Padang). Pada penelitian Evaluasi Kinerja Pelayanan Perawat menggunakan metode fuzzy mamdani dan hasil dari evalusi dapat menghasilkan suatu nilai yang dapat dipergunakan dalam mengukur kinerja perawat pada RSIA Siti Hawa Padang. Dari penelitian tersebut penulis mencoba menggunakan metode mamdani dalam permasalahan ini.

\section{TINJAUAN PUSAKA}

\subsection{Fuzzy Logic}

Logika fuzzy merupakan salah satu komponen pembentuk soft computing. Logika fuzzy pertama kali diperkenalkan oleh Prof. Lotfi A. Zadeh padatahun 1965. Dasar dari logika fuzzy adalah teori himpunan fuzzy. Pada teori himpunan fuzzy, peranan derajat keanggotaan sebagai penentu keberadaaan elemen dalam suatu himpunan sangatlah penting. Nilai keanggotaan atau derajat keanggotaan atau membership function menjadi ciri utama dari penalaran dengan logika fuzzy tersebut. Dalam banyak hal, logika fuzzy digunakan sebagai suatu cara untuk memetakan permasalahan dari input menuju output yang diharapkan. Beberapa contoh yang dapat diambil antara lain (Dini Rusmiyati Andari, 2009):

1) Manajer pergudangan mengatakan kepada manajer produksi seberapa banyak persediaan barang pada akhir minggu ini, kemudian manajer produksi akanmenetqapkan jumlah barang yang akan diproduksi esok hari.

2) Seorang pegawai melakukan tugasnya dengan kinerja yang sangat baik, kemudia atas akanmemberikan reward, yang sesuai dengan kinerja pegawai tersebut.
Fuzzy Mamdani

Metode mamdani sering dikenal dengan metode Max-min. Metode ini diperkenalkan oleh Ebrahim Mamdani pada tahun 1975. Untuk mendapatkan output, diperlukan 4 tahapan (Fithriani Matondang dkk, 2010):

1) Pembentukan himpunan fuzzy

Pada metode mamdani baik variabel inputmaupun variabel output dibagi menjadi satu atau lebih himpunan fuzzy.

2) Aplikasi fungsi implikasi

Pada metode mamdani, fungsi implikasi yang digunakan adalah min.

3) Kompisisi aturan

Tidak seperti penalaran momoton, apabila sistem terdiri dari beberapa aturan, maka inferensi diperoleh dari kumpulan dan kolerasi.Ada tiga metode yang digunakan dalam melakukan inferensi sistem fuzzy, yaitu max, additive dan probabilistik OR (probor).

Metode Max (Maximum)

Pada metode ini, solusi himpunan fuzzy diperoleh dengan cara mengambil nilai maksimum atruan, kemudian menggunakannya untuk memodifikasi daerah fuzzy, dan mengaplikasikannya ke output dengan menggunakan operator OR (union). Jika semua proposisi telah dievaluasi, maka output akan berisi suatuhimpunan fuzzy yang merefleksikan komtribusi dari tiap tiap proposisi.

Secara umum dapat dituliskan:

$$
\mu \mathrm{sf}[\mathrm{xi}]=\max (\mu \mathrm{usf}[\mathrm{Xi}], \mu \mathrm{kf}[\mathrm{Xi}])
$$

Dengan :

$\mu \mathrm{sf}[\mathrm{Xi}]=$ nilai keanggotaannya solusi fuzzy sampai aturan ke- $i$.

$\mu \mathrm{kf}[\mathrm{Xi}]=$ nilai keanggotaan konsekuan fuzzy aturan ke- $i$.

Misalkan ada 3 aturan (proposisi) sebagai berikut:

[R1] IF Biaya Produksi RENDAH and Permintaan NAIK THEN Produksi Barang

BERTAMBAH;

[R2] IF Biaya Produksi STANDARTHEN Produksi Barang NORMAL;

[R3] IF Biaya Produksi TINGGI and Permintaan TURUN THEN Produksi barang BERKURANG;

Proses inferensi dengan menggunakan metode Max dalam melakukan komposisi ini sering disebut dengan nama MAX-MIN atau MIN-MAX atau MAMDAI 
Metode Additive (Sum)

Pada metode ini, solusi himpunan fuzzy diperoleh dengan cara melakukan bounded-sum terhadap semua output daerah fuzzy secara umum dituliskan:

$$
\mu \mathrm{sf}(\mathrm{xi})=\min (1, \mu \mathrm{sf}(\mathrm{xi})+\mu \mathrm{kf}(\mathrm{xi})
$$

dengan:

$\mu \mathrm{sf}[\mathrm{Xi}]=$ nilai keanggotaannya solusi fuzzy sampai aturan ke- $i$

$\mu \mathrm{kf}[X i]=$ nilai keanggotaan konsekuan fuzzy aturan ke- $i$

Metode Probalistik OR (probor)

Pada metode ini, solusi himpunan fuzzy diperoleh dengan cara melakukan product terhadap semua output daerah fuzzy. Secara umum dituliskan:

$$
\mu \mathrm{sf}(\mathrm{xi})=(\mu \mathrm{sf}(\mathrm{xi})+\mu \mathrm{kf}(\mathrm{xi}))-(\mu \mathrm{sf}(\mathrm{xi}) * \mu \mathrm{kf}(\mathrm{xi}))
$$

dengan:

$\mu \mathrm{sf}[X i]=$ nilai keanggotaannya solusi fuzzy sampai aturan ke- $i$

$\mu \mathrm{kf}[X i]=$ nilai keanggotaan konsekuan fuzzy aturan ke- $i$

Penegasan (defuzzy)

Input proses defuzzifikasi adalah suatu himpunan fuzzy yang diperoleh dari komposisi aturasn aturan fuzzy, sedangkan output yang dihasilkan merupakan suatu bilangan pada domain himpunan fuzzy dalam range tertentu, maka harus dapat diambil suatu nilai crisp tertentu sebagai output.

\subsection{Satuan Kredit Kegiatan Mahasiswa (SKKM)}

Tujuan dari dibuatnya Satuan Kredit Kegiatan Mahasiswa (SKKM) adalah meningkatkan peranan dan partisipasi aktif mahasiswa dalam setiap kegiatan kemahasiswaan dalam rangka peningkatan wawasan akademis dan non akademis para mahasiswa, untuk meningkatkan rasa kebersamaan dan persaudaraan antara mahasiswa, dan memberikan pernghargaan atas partisipasi aktif mahasiswa dalam setiap kegiatan kemahasiswaan.

Dalam penilaian Satuan Kredit Kegiatan Mahasiswa (SKKM) ada beberapa indikator yang dijadikan alat ukur untuk penilaian SKKM diantaranya adalah:

1) Bidang Akademik: merupakan bidang penilaian yang melibatkan kepanitian dan partisipasi mahasiswa dalam pembuatan atau penyajian makalah / moderator ilmiah, melakukan penelitian / karyatulis, seminar dan workshop.

2) Bidang Minat Bakat dan Olahraga: merupakan bidang penilaian yang melibatkan kepanitian dan partisipasi mahasiswa dalam keiukusertaan dalam turnamen / kompetisi minat dan bakat yang diselenggarakan oleh kampus maupun diluar kampus
3) Bidang Pengabdian Masyarakat : merupakan bidang penilaian yang melibatkan kepanitian dan partisipasi mahasiswa dalam keikutsertaan mahasiswa pada pengabdian masyarakat, bakti sosial, donor darah serta kegiatan-kegiatan pengabdian kepada masyarakat

4) Kegiatan Wajib : merupakan bidang penilaian yang melibatkan kepanitian dan partisipasi mahasiswa dalam kegiatan wajib yang diikuti oleh mahasiswa seperti jalan sehat, pentas musik serta gema mahasiswa teknologi informasi (GMTI)

Jadi ada beberapa faktor dalam penilaian tingkat kemampuan non-akademik mahasiswa melalui satuan kredit kegiatan mahasiswa.

\section{PEMBAHASAN}

\subsection{Analisa Data}

Dalam analisa ini penulis menganalisa dan mengelompok kelompokkan data untuk memudahkan dalam mengerjakan perancangan sistem yang telah direncanakan sebelumnya sesuai dengan variabel variabel yang dibutuhkan, guna untuk menganalisa data yang diperlukan dalam perancangan sistem ini. FIS (Fuzzy Inference System) dibangun dengan dua metode, yaitu mamdani dan metode sugeno, Keluaran fuzzy mamdani berupa fuzzy set dan bukan sekedar inverse dari fungsi keanggotaan output. Dengan kata lain untuk menghitung harga keluaran dari IF-THEN rule, metode mamdani harus menghitung luas dibawah kurva fuzzy set pada bagian keluaran (THEN-part). Selanjutnya dalam proses defuzzifikasi, metode mamdani harus menghitung rata rata (centroid) luas yang diboboti dari semua fuzzy set keluaran dari rule, kemudian mengisikan rata-rata tersebut ke variabel keluaran FIS.

Di dalam tahap menganalisa dan merancang sistem terdapat 5 variabel yang digunakan dan di perlukan antara lain: Kepemimpinan, administrasi, manajemen, teamwork, partisipan.

Untuk nilai kepemimpinan dibagi menjadi 4 bagian seperti pada Tabel 1. berikut:

Tabel 1. Nilai Kepemimpinan

\begin{tabular}{|l|l|l|}
\hline Semesta & $\begin{array}{l}\text { Himpunan } \\
\text { Fuzzy }\end{array}$ & Domain Nilai \\
\hline Point 0-100 & Kurang & $0-50$ \\
\cline { 2 - 3 } & Cukup & 4070 \\
\cline { 2 - 3 } & Baik & $60-90$ \\
\cline { 2 - 3 } & Sangat Baik & $80-100$ \\
\hline
\end{tabular}

Function Variabel Kepemimpinan

Terdapat 4 himpunan fuzzy untuk variabel kepemimpinan antara lain : kurang, cukup, baik, dan sangat baik. . Himpunan fuzzy tidak pernah memiliki domain (0-50) dengan derajat keanggotaan kurang tertinggi terdapat pada nilai 40 , jika nilai 
variabel semakin tinggi dan melebihi nilai 40 maka semakin mendekati kadang-kadang, himpunan fuzzy kurang dipresentasikan dengan bahu kiri, himpunan fuzzy kurang sebagai berikut:

4kurang $\left[\mathrm{X}_{1}\right]\left\{\begin{array}{l}1 ; \mathrm{X}_{1} \leq 40 \\ \frac{40-\mathrm{X} 1}{5} ; 40 \leq \mathrm{X}_{1} \leq 50 \\ 0 ; \mathrm{X}_{1} \geq 0\end{array}\right.$

Untuk himpunan fuzzy cukupmempunyai domain $(40-70)$ dengan derajat keanggotan kadang kadang, tertinggi nilainya terdapat pada 55, jika nilai variabel semakin tinggi dan melebihi nilai 55 maka semakin mendekati sering. Himpunan fuzzy kadang kadang diimplementasikan dengan fungsi keanggotaan segitiga, himpunan fuzzy kadang kadang sebagai berikut;

чcukup $\left[\mathrm{X}_{1}\right]\left\{\begin{array}{l}0 ; \mathrm{X}_{1} \leq 40 \text { atau } \mathrm{X}_{1} \geq 70 \\ \frac{\mathrm{X} 1-40}{15} ; 40 \leq \mathrm{X}_{1} \leq 55 \\ \frac{70-\mathrm{X} 1}{15} ; 55 \leq \mathrm{X}_{1} \leq 70\end{array}\right.$

Untuk himpunan fuzzy baik mempunyai domain (60-90) dengan derajat keanggotan sering, tertinggi nilainya terdapat pada 75 , jika nilai variabel semakin tinggi dan melebihi nilai 75 maka semakin mendekati selalu. Himpunan fuzzy sering di implementasikan dengan fungsi keanggotaan segitiga, himpunan fuzzy sering sebagai berikut;

ubaik $\left[X_{1}\right]\left\{\begin{array}{l}0 ; X_{1} \leq 60_{\text {atau }} X_{1} \geq 90 \\ \frac{X 1-60}{15} ; 60 \leq X_{1} \leq 75 \\ \frac{90-X 1}{15} ; 75 \leq X_{1} \leq 90\end{array}\right.$

Sedangkan untuk himpunan fuzzy sangat baik mempunyai domain (80-100) dengan derajat keanggotaan selalu, tertinggi nilainya terdapat pada 90, apabila nilai kurang dari 90 maka mendekati sering, himpunan fuzzy selalu di presentasikan dengan bahu kanan.

чsangatbaik $\left[X_{1}\right]\left\{\begin{array}{l}0 ; X_{1} \leq 80 \\ \frac{x 1-60}{10} ; 70 \leq X_{1} \leq 90 \\ 1 ; X_{1} \geq 90\end{array}\right.$

Contoh Penerapan Fuzifikasi :

Total point secara keseluruhan pada kepemimpinan: 70, administrasi: 75, manajemen: 89, teamwork: 80 , dan partisipan: 70 .

1. Kepemimpinan $=70$

ykurang [70] $\left\{\begin{array}{c}0 ; \mathrm{X}_{1} \leq 40 \\ \frac{40-\mathrm{X} 1}{5} ; 40 \leq \mathrm{X}_{1} \leq 50 \\ 0 ; \mathrm{X}_{1} \geq 0\end{array}\right.$

$0 ; X_{1} \geq 0$

$$
\begin{aligned}
& \text { чcukup[70] }\left\{\begin{array}{l}
0 ; X_{1} \leq 40 \text { atau } 64 \geq 70 \\
\frac{70-40}{15} ; 40 \leq 64 \leq 55 \\
\frac{70-70}{15} ; 55 \leq 64 \leq 70 \\
=0
\end{array}\right. \\
& \text { чbaik[70] }\left\{\begin{array}{l}
0 ; X_{1} \leq 60 \text { atau } X_{1} \geq 90 \\
\frac{70-60}{15} ; 60 \leq X_{1} \leq 75 \\
\frac{90-70}{15} ; 75 \leq X_{1} \leq 90 \\
=0,67
\end{array}\right. \\
& \text { чsangatbaik[70] } \begin{array}{c}
0 ; X_{1} \leq 80 \\
\frac{\pi 1-60}{10} ; 70 \leq X_{1} \leq 90 \\
1 ; X_{1} \geq 90
\end{array}
\end{aligned}
$$

Administrasi: 75

$$
\begin{aligned}
& \text { чkurang [75] }\left\{\begin{array}{l}
1 ; 75 \leq 30 \\
\frac{30-75}{5} ; 30 \leq \mathrm{X}_{3} \leq 40 \\
0 ; \mathrm{X}_{3} \geq 0
\end{array}\right. \\
& \text { чcukup[75] }\left\{\begin{array}{l}
0 ; \mathrm{X}_{3} \leq 30 \text { atau } \mathrm{X}_{3} \geq 60 \\
\frac{\mathrm{x} 3-30}{15} ; 30 \leq \mathrm{X}_{3} \leq 45 \\
\frac{60-75}{15} ; 45 \leq \mathrm{X}_{3} \leq 60 \\
=0
\end{array}\right.
\end{aligned}
$$

usangatbaik[75] $\left\{\begin{array}{l}0 ; X_{3} \leq 70 \\ \frac{X_{3}-70}{15} ; 70 \leq X_{3} \leq 85 \\ 1 ; X_{3} \geq 85\end{array}\right.$

Manajemen $=89$ 
чcukup[89] $\left\{\begin{array}{l}0 ; \mathrm{X}_{2} \leq 40 \text { atau } \mathrm{X}_{2} \geq 70 \\ \frac{\mathrm{x}-40}{15} ; 40 \leq \mathrm{X}_{2} \leq 55 \\ \frac{70-\mathrm{X} 2}{15} ; 55 \leq \mathrm{X}_{2} \leq 70\end{array}\right.$

$0 ; X_{2} \leq 60_{\text {atau }} X_{2} \geq 90$

4baik[89] $\left\{\begin{array}{l}\frac{89-60}{15} ; 60 \leq \mathrm{X}_{2} \leq 75 \\ \frac{90-89}{15} ; 75 \leq \mathrm{X}_{2} \leq 90 \\ =0,06\end{array}\right.$

usangatbaik[89] $\left\{\begin{array}{l}0 ; 89 \leq 80 \\ \frac{89-80}{10} ; 70 \leq 89 \leq 90 \\ 1 ; 89 \geq 90\end{array}\right.$

Teamwork $=80$

4kurang [80] $\left\{\begin{array}{l}1 ; 80 \leq 30 \\ \frac{30-\mathrm{X} 4}{5} ; 30 \leq \mathrm{X}_{4} \leq 40 \\ 0 ; \mathrm{X}_{4} \geq 0\end{array}\right.$

чcukup[80] $\left\{\begin{array}{l}0 ; 80 \leq 30 \text { atau } \mathrm{X}_{4} \geq 60 \\ \frac{80-30}{15} ; 30 \leq \mathrm{X}_{4} \leq 45 \\ \frac{60-30}{15} ; 45 \leq \mathrm{X}_{4} \leq 60\end{array}\right.$

qbaik[80] $\left\{\begin{array}{l}0 ; \mathrm{X}_{4} \leq 50_{\text {atau }} \mathrm{X}_{4} \geq 90 \\ \frac{\mathrm{x} 4-50}{20} ; 50 \leq \mathrm{X}_{4} \leq 70 \\ \frac{90-80}{20} ; 70 \leq \mathrm{X}_{4} \leq 90\end{array}\right.$

чsangatbaik[80] $\left\{\begin{array}{l}0 ; 80 \leq 70 \\ \frac{80-70}{15} ; 70 \leq 80 \leq 85 \\ 1 ; \mathrm{X}_{4} \geq 85\end{array}\right.$

Partisipan $=70$

4kurang [70] $\left\{\begin{array}{l}0 ; \mathrm{X}_{1} \leq 40 \\ \frac{40-\mathrm{X}_{1}}{5} ; 40 \leq \mathrm{X}_{1} \leq 50 \\ 0 ; \mathrm{X}_{1} \geq 0\end{array}\right.$

чcukup[70] $\left\{\begin{array}{l}0 ; \mathrm{X}_{1} \leq 40 \text { atau } 64 \geq 70 \\ \frac{70-40}{15} ; 40 \leq 64 \leq 55 \\ \frac{70-70}{15} ; 55 \leq 64 \leq 70\end{array}\right.$

$=0$

$$
\begin{aligned}
& \text { ubaik[70] }\left\{\begin{array}{l}
0 ; X_{1} \leq 60_{\text {atau }} X_{1} \geq 90 \\
\frac{70-60}{15} ; 60 \leq X_{1} \leq 75 \\
\frac{90-70}{15} ; 75 \leq X_{1} \leq 90 \\
=0,67
\end{array}\right. \\
& \text { usangatbaik[70] }\left\{\begin{array}{c}
0 ; X_{1} \leq 80 \\
\frac{x 1-60}{10} ; 70 \leq X_{1} \leq 90 \\
1 ; X_{1} \geq 90
\end{array}\right.
\end{aligned}
$$

\subsection{Penalaran (Inferensi)}

Tahap ini merupakan penentuan rule-rule dari sistem logika fuzzy, aturan-aturan dapatdibentuk untuk menyatakan relasi antara input danoutput. Tiap aturan merupakan implementasi.Operator yang digunakan untuk menghubungkanaturan-aturan input adalah operator And yang menggambarkan antara input-output adalah IF-THEN.

If (Kepemimpinan is Baik) and (Administrasi is SangatBaik) and (Manajemen is Baik) and (Teamwork is Baik) and (Partisipan is Baik) then (output1 is Aktif)

$\alpha$ - hasil point skkm $=\mu \mathrm{KPbaik} \cap \mu$ ADsangatbaik $\cap$ $\mu \mathrm{MMbaik} \cap \mu \mathrm{TWbaik} \cap \mu \mathrm{PSba}$ ik

$=\mu \mathrm{KPbaik}(70) \cap \mu \mathrm{ADsangatbaik}$ (75) $\cap \mu$ MMbaik (89) $\cap$ $\mu$ TWbaik $(80) \cap \mu$ PSbaik (70) $=\min (0,67 ; 0,75 ; 0,06 ; 0,50$ ;0,67)

$=0,06$

\subsection{Defuzifikasi}

Tahap ini disebut juga tahap penegasaninput dan proses. Penegasan ini adalah suatu himpunan kabur yang diperoleh dari komposisiaturan-aturan kabur, sedangkan output yang dihasilkan merupakan suatu bilangan pada domain himpunan kabur tersebut.

Untuk predikat mahasiswa dapat dilihat dari Tabel 2. berikut:

Tabel 2. Tabel Predikat

\begin{tabular}{|l|l|l|}
\hline Point & Predikat & Domain Nilai \\
\hline Point 0-100 & Kurang Aktif & $0-50$ \\
\cline { 2 - 3 } & Cukup Aktif & 4070 \\
\cline { 2 - 3 } & Aktif & $60-90$ \\
\cline { 2 - 3 } & Sangat Aktif & $80-100$ \\
\hline
\end{tabular}


Hasil Rule seperti data di atas adalah;

$Z=\frac{70.0,67+75.0,75+89.0 .06+80.0,5+70.0,67}{0.67+0.75+0.06+0,5+0,67}$

$Z=\frac{46.9+56.25+5.34+40+46,9}{2.65}$

$Z=\frac{195,39}{2.65}$

$\mathrm{Z}=73.73$

Maka dari percobaan diatas terdapat hasil nilai 73.73 yang termasuk dalam predikat mahasiswa yang aktif terlihat dari domain antara 60-90 tergolong aktif.

\section{KESIMPULAN}

Dari hasil penelitian tersebut maka metode fuzzy untuk penelitian penilaian tingkat kemampuan non-akademik mahasiswa melalui satuan kredit kegiatan mahasiswa, sesuai hasil yang di inginkan dan metode fuzzy dapat mengevaluasi mahasiswa dan membantu dalam penilaian tingkat kemampuan non-akademik mahasiswa dilihat dari hasil percobaan dengan total point secara keseluruhan pada kepemimpinan: 70, administrasi: 75, manajemen: 89 , teamwork: 80 , dan partisipan: 70 diperoleh hasil evaluasi mahasiswa dengan predikat aktif.

\section{DAFTAR PUSTAKA}

AKLANI, SYAEFUL ANAS. 2014. Metode Fuzzy Logic Untuk Evaluasi Kinerja Pelayanan Perawat (Studi Kasus: RSIA Siti Hawa Padang). Pendidikan Informatika STKIP PGRI Sumbar.

AMRI, F., NABABAN, E.B. \& SYAHPUTRA, M.F. 2012. Artificial Bee Colony Algorithm untuk menyelesaikan Travelling Salesman Problem. Jurnal Dunia Teknologi Informasi. 1(1): 8-13.

ANDARI, RR. DINI RUSMIYATI. 2009. Aplikasi Fuzzy Database Evaluasi Kinerja Pegawai di SMK Negeri 02 Bangkalan Menggunakan JSP.

ARIFIN, ZAENAL. 2009. Evaluasi Pembelajaran. Bandung: Remaja Rosdakarya hal 2.

KEMAHASISWAAN. 2015. Buku Pedoman Satuan Kredit Kegiatan Mahasiswa. Denpasar.

KUSUMA DEWI. 2010. Aplikasi Logika Fuzzy Untuk Pendukung Keputusan Edisi 2, Graha Ilmu.

MATONDANG, FITHRIANI dkk. 2010. Fuzzy Logic Metode Mamdani Untuk Membantu Diagnosa Dini Autism Spectrum Disorder. UIN Maulana Malik Ibrahim Malang
PURWANTO, M. NGALIM. 2010. Prinsip-prinsip dan Teknik Evaluasi Pengajaran. Bandung: Remaja Rosdakarya hal 3.

RAKHMAWATI, ESA. 2013. Pengembangan Penilaian Kinerja Siswa (Students Performance Assessment) Dalam Menemukan Rumus Pythagoras. Undergraduate thesis, UIN Sunan Ampel Surabaya. 